\title{
Thermal Characteristics Analysis for Motorized Spindle System of CNC Machining Center
}

\author{
Xiaolei Deng ${ }^{1,2,3}$, Xinghui Zhang ${ }^{1}$, Mucheng Zhang ${ }^{1}$, Yibo Zhou ${ }^{1}$, Huan Lin ${ }^{1}$ and Jianchen Wang ${ }^{1,3}$ \\ ${ }^{1}$ Key Laboratory of Air-driven Equipment Technology of Zhejiang Province, Quzhou University, Quzhou 324000, China; \\ ${ }^{2}$ Key Laboratory of 3D Printing Process and Equipment of Zhejiang Province, Zhejiang University, Hangzhou 310027, China; \\ ${ }^{3}$ Zhejiang Yonglida CNC Technology Co., Ltd., Quzhou 324000, China
}

\begin{abstract}
Based on the comprehensive analysis of the heat sources of the motorized spindle system, the thermal loads, including the heat generation of bearing friction and the electromagnetic loss of the built-in motor, are carried out for a machining center motorized spindle system. And then, the convective heat transfer coefficients of the whole spindle system are analyzed. The thermal characteristics of the motorized spindle system are calculated by finite element analysis. The steady state temperature field distribution of the motorized spindle is obtained. It provides some references for improving the thermal characteristics of the motorized spindle and reducing the difficulty of thermal error compensation.
\end{abstract}

\section{Introduction}

The motorized spindle system will produce deformation due to stress in the process, in addition to large amounts of heat, which can generate thermal deformation. These thermal deformations can not only short the working life of the spindle, but also affect the processing accuracy of the machine tool. A large number of studies have shown that in the factors that affect the accuracy of machine tool, the thermal error caused by external environment and internal heat sources are the largest error source of precision machining machine such as $\mathrm{CNC}(\mathrm{Computer}$ Numerical Control) machine tools, which accounts for $40-70 \%$ of the total manufacturing error $[1,2]$.

Therefore, it is necessary to analyze the temperature field of the motorized spindle system and grasp the thermal characteristics of the motorized spindle system, so as to find a way to effectively reduce the temperature rise of the spindle, and reduce the thermal errors of the spindle system.

In this paper, a machining center's motorized spindle system was taken as an example to study its heat and cooling mechanism. Using finite element software ANSYS, the steady temperature field of the motorized spindle system were obtained.

\section{Calculation of the thermal load of the motorized spindle system}

There are two main sources of heat source in the motorized spindle system, including the heat due to loss of the built-in motor and the heat due to friction of the spindle-bearing.

\subsection{Heat calculation of built-in motor}

The heat generated by the motor in the motorized spindle system can be divided into heat generation of rotor and heat generation of the stator. The power of the motorized spindle system from the input power $P_{1}$ can be calculated by Eq. 1

$$
P_{1}=3 U_{1} I_{1} \cos \varphi_{1}
$$

where, $U_{1}$ is phase voltage of stator winding, $I_{1}$ is phase current of stator winding, $\cos \varphi_{1}$ is power factor of stator winding.

After motorized spindle system take power $P_{1}$ suction, one part is consumed on the stator winding resistance $\left(r_{1}\right)$, i.e. copper loss $P_{C u 1}$ which canbe calculated from

$$
P_{C u 1}=3 I_{1}^{2} r_{1}
$$

Another part is consumed on the stator iron core, i.e. iron loss $P_{F e}$ which canbe calculated from

$$
P_{F e}=3 I_{0}^{2} r_{m}
$$

So the total power loss of the stator $\left(P_{d}\right)$ is $P_{C u 1}$ and $P_{F e}$.

The heat generation rate of the stator [3]

$$
\overline{q_{d}}=\frac{P_{d}}{V_{d}}
$$

where, $V_{d}$ is the volume of the stator.

In addition, the rest of the power is transferred from the stator to the rotor through the electromagnetic induction, which is called the electromagnetic power $P_{M}$ can be calculated by Eq. 5 


$$
P_{M}=P_{1}-P_{C u 1}-P_{F e}
$$

Due to the low frequency of the rotor in normal operation, the iron consumption of the rotor is very small, usually negligible, so the rotor power loss $P_{z}$ can be equivalent to the copper consumption of the rotor.Thus the heat generation rate of the rotor is

$$
\overline{q_{z}}=\frac{P_{z}}{V_{z}}
$$

where, $V_{z}$ is the volume of the rotor.

\subsection{Calculation of heat for bearing}

According to Eq.7 [1], the friction moment of the bearing is mainly composed of two parts: the viscous friction moment and the load friction moment, and the calculation formula as following

$$
M=10^{-7} f_{0}(v n)^{\frac{2}{3}} d_{m}^{3}+f_{1} P_{1} d_{m}
$$

where, $M$ is the friction torque of bearings, $f_{0}$ is depends on the type of bearing, $v$ is motion viscosity of lubricants at working temperature, $n$ is rotating speed of inner ring of bearing, $d_{m}$ is circle diameter of bearing, $f_{1}$ is coefficient related to bearing type and load, $P_{1}$ is calculation load determining the friction torque of bearing.

In addition, the spin motion of the rolling body is an important factor in heating. And the frictional moment in the contact area between the rolling body and the inner ring is [4]

$$
M_{S i}=\frac{3 \mu_{S i} Q_{i} a_{i} \varepsilon_{i}}{8}
$$

where, $\mu_{S i}$ is the friction coefficient of the rolling element and the inner ring raceway, $a_{i}$ is Hertz contact ellipse long axis of rolling element and the inner ring raceway, $Q_{i}$ is the normal contact load of the rolling element and the inner ring raceway, $\varepsilon_{i}$ is the second complete integral of Hertzian contact ellipse for rolling element and the inner ring raceway.

The friction power is generated by the bearing as following [5]

$$
H=\frac{2 \pi n_{1}}{60} M+\omega_{S i} M_{S i}
$$

where, $n_{1}$ is the rotation speed of the spindle, $\omega_{S i}$ is spin angular velocity at the contact part between the roller and the inner raceway.

The heat generation rate of the bearing is defined as Eq.10 [6]

$$
\left\{\begin{array}{l}
q_{f}=\frac{H_{f}}{V_{f}} \\
q_{a}=\frac{H_{a}}{V_{a}}
\end{array}\right.
$$

where, $q_{f}$ is the heat generation rate of the front bearing, $q_{a}$ is the heat generation rate of the rear bearing, $H_{f}$ is the friction power of the front bearing, $H_{a}$ is the friction power of the rear bearings, $V_{f}$ is the volume of the front bearing, $V_{a}$ is the volume of the rear bearings.

\section{Calculation of the thermal boundary condition of the motorized spindle system}

\subsection{Convective heat transfer coefficient between stator cooling water jacket and cooling water}

The stator outer ring of the motorized spindle system has a rectangular spiral cooling water jacket to cool the stator and the outer shell. The Nusselt criterion equation, under forced convection, convective heat transfer coefficient can be alculated by Eq.11

$$
a=\frac{\mathrm{Nu} \cdot \lambda}{L}
$$

where, $\lambda$ is the thermal conductivity of the ambient fluid, $\mathrm{Nu}$ is Nusselt number, $L$ is the equivalent length of spiral cooling water jacket.

The Nusselt number of cooling water in laminar state can be calculated by Eq.12

$$
\left\{\begin{array}{l}
\mathrm{Nu}=1.86\left(\operatorname{Re} \operatorname{Pr} \frac{D}{L}\right)^{\frac{1}{3}}\left(\frac{\eta_{f}}{\eta_{w}}\right)^{0.14} \\
\mathrm{R}_{\mathrm{e}}=\frac{v_{1} \cdot D}{v_{f}}
\end{array}\right.
$$

where, $\operatorname{Pr}$ is the Prandtl number, $\eta_{f}$ is fluid dynamic viscosity, $\eta_{w}$ is dynamic viscosity of the fluid under the cooling water jacket wall temperature, $v_{1}$ is the flow rate of cooling water, $D$ is stereotyped size of geometric features, $v_{f}$ is kinematic viscosity of fluid in qualitative temperature.

The calculation method of convective heat transfer coefficient between the annular groove and the cooling water of the front bearing block is the same as the method above.

\subsection{Convective heat transfer coefficient between the cooling gas and the stator}

The average speed of cooling gas between the rotor and the stator is defined as follows

$$
\bar{u}=\sqrt{u_{a x}^{-2}+u_{r a d}^{-2}}
$$

The average velocity of the axial cooling gas through the air gap between the stator and rotor is defined as follows

$$
\bar{u}_{a x}=\frac{v_{g}}{A_{a x}}=\frac{v_{g}}{\frac{\pi}{4}\left(d^{2}{ }_{\text {stator }}-d^{2}{ }_{\text {rotor }}\right)}
$$

where, $v_{g}$ is the volume flow rate of cooling gas, $A_{a x}$ is the axial cross-sectional area of gap, $d_{\text {stator }}$ is the stator inner circle diameter, $d_{\text {rotor }}$ is the rotor outer circle diameter. 
In addition, the average velocity of the cooling gas is subjected to the shear action of the circumferential direction of the stator and the rotor, resulting in the tangential mean velocity.

$$
\bar{u}_{\text {rad }}=\frac{v_{\text {sur }}}{2}=\frac{\omega_{\text {rotor }} d_{\text {rotor }}}{4}
$$

where, $v_{\text {sur }}$ is the velocity of the rotor surface.

\subsection{Convective heat transfer coefficient of the rotor end}

When the spindle is running, the rotor end is mainly convection and radiation heat transfer with the surrounding cooling air. The compound heat transfer coefficient is as follows [7]

$$
a_{t}=28\left(1+\left(\frac{3 \pi n_{1} d_{a}}{400}\right)^{0.5}\right)
$$

where, $a_{t}$ is the convection heat transfer coefficient at the rotor end, $d_{a}$ is the average diameter of the rotor end.

\subsection{Convective heat transfer coefficient between bearing and lubricating gas}

The heat transfer coefficient between the bearing and the lubricating gas can be determined by Eq. 17

$$
\alpha=\left(c_{0}+c_{1} u^{c_{2}}\right)
$$

where, $c_{0}, c_{1}$ and $c_{2}$ are determined by the constant of the test; $u$ is the average velocity of the compressed gas in the bearing.

The average velocity of compressed air in a rotating bearing can be obtained by the axial and tangential air flow.

$$
u=\left[\left(\frac{V_{1}}{A_{a}}\right)^{2}+\left(\frac{\omega d_{m}}{2}\right)^{2}\right]^{\frac{1}{2}}
$$

where, $V_{1}$ is the flow of the actual gas of the bearing; $\omega$ is the rotational angular velocity of the spindle, $A_{a}$ is the area when the axial air flow passes through the bearing, $d_{m}$ is the average diameter of the inner and outer ring of the bearing.

\subsection{Heat transfer coefficient between the outer shell and the surrounding air}

When the motorized spindle system is running, the natural convection heat transfer with the surrounding air is caused by the surface temperature of the shell is higher than the ambient air. Meanwhile, the spindle shell also radiate heat with the surrounding air. The heat transfer coefficient of the composite heat transfer is $\alpha_{s}$

$$
\alpha_{s}=\alpha_{c}+\alpha_{r}
$$

where, $\alpha_{c}$ is convective heat transfer coefficient which is converted from radiation, $\alpha_{r}$ is natural convection heat transfer coefficient, $\alpha_{s}$ is compound heat transfer coefficient.

\section{Thermal analysis of motorized spindle system}

Taking one motorized spindle system as the research object, the thermal characteristics of the spindle system are analyzed according to the load and boundary conditions calculated by the above thermal characteristic models. It is known that the temperature of the external environment is $22^{\circ} \mathrm{C}$, the spindle speed is $42000 \mathrm{rpm}$, the cooling water flow is $1.07 \mathrm{~L} / \mathrm{min}$, and the gas supply pressure of the oil lubrication system is $0.23 \mathrm{MPa}$. And Ansys workbench software is employed to gain the steady temperature field distribution of the spindle system, as shown in Figure 1.As can be seen from figure 1, the maximum temperature appears at the front bearing is about $154.06{ }^{\circ} \mathrm{C}$, and the maximum temperature of shaft is about $140.38^{\circ} \mathrm{C}$.

\begin{tabular}{l} 
B: Steady-State The \\
Temperature \\
Type: Temperature \\
Unit: ${ }^{\circ} \mathrm{C}$ \\
Time: 1 \\
2018/2/1 11:12 \\
154.06 Max \\
141.47 \\
\hline 128.89 \\
\hline 116.3 \\
103.72 \\
\hline 91.131 \\
78.546 \\
65.961 \\
$\mathbf{5 3 . 3 7 5}$ \\
$\mathbf{4 0 . 7 9}$ Min \\
Figure 1. The
\end{tabular}

Figure 1. The steady state temperature distribution of the motorized spindle system

\section{Conclusions}

In this paper, a thermal load and boundary condition calculation model of motored spindle system for one machining center was established, and Ansysworkbench was employed to simulate and solve. Through the analysis, the steady state temperature distribution of the motorized spindle system was gotten. The research in this paper will provide some valuable reference for the thermal structure design and thermal error compensation of the motorized spindle system.

\section{Acknowledgment}

This research was financially supported by National Natural Science Foundation of China (No. 51605253), Zhejiang Provincial Natural Science Foundation of China (No. LY16E050011) and Quzhou Science and Technology Planning Project (2016Y003\&2015Y007).

\section{References}

1. DENG X L. Analysis Techniques of Thermal Characteristics for CNC Machine Tool Spindle System [M].Hangzhou: Zhejiang University Press, 2017. (in Chinese) 
2. Mayr J, Jędrzejewski J, Uhlmann E, et al. Thermal Issues in Machine Tools [J]. CIRP Annals-Manufacturing Technology, 2012, 61(2): 771-791.

3. Huang X M.FEA of Thermal Properties for High Speed Motorized Spindle [D].Guangzhou: Guangdong University of Technology, 2003. (In Chinese)

4. Deng S E, Jia Q Y. Design Principle of Rolling Bearing [M].Beijing: China Standards Press, 2008.(In Chinese)
5. Brauer J R, Mayergoyz I D. Finite-element Computation of Nonlinear Magnetic Diffusion and Its Effects When Coupled to Electrical, Mechanical, and Hydraulic Systems [J]. IEEETransactions on Magnetics, 2004, 40(2): 537-540.

6. Guo J. Research on Motorized Spindle's Thermal Properties Based on Thermal Contact [D].Guangzhou: Guangdong University of Technology, 2005. (In Chinese)

7. Ding S N. Heating and Cooling of Large Motor [M].Beijing: Science Press, 1992. 